\title{
In the field, Canadians diagnose Marburg
}

Using a portable lab they had packed into suitcases and hauled halfway around the world, a Winnipeg virologist and a lab technician rendered life-or-death verdicts during the recent outbreak of Marburg in Angola.

Over a 3 -week period in March and April, Dr. Heinz Feldmann and Allen Grolla tested blood samples for Marburg virus, a hemorrhagic fever that has been raging in Uige, Angola, since February.

A positive result meant virtual certainty of death. Marburg has a mortality rate of $90 \%$.

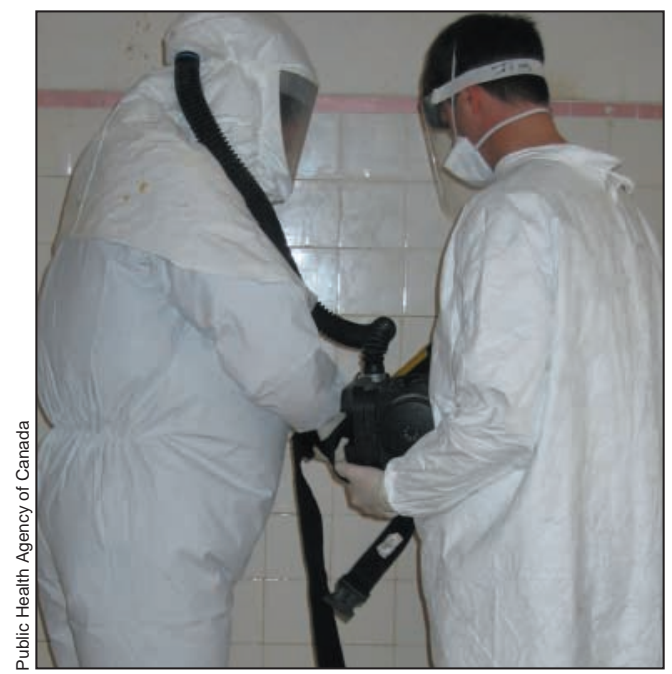

Dr. Heinz Feldmann of the Public Health Agency of Canada suits up, with the help of Dr. Jim Strong, to enter the infectious area of the hospital in Uige, Angola, where he was testing for Marburg virus.

"The most frustrating thing is that, after 20 years, I still can't treat anyone. I still can't do very much," Feldmann, a specialist in rare pathogens, said after returning from Uige on Apr. 21.

"I would love to provide help," said Feldmann, acting director of zoonotic diseases at the National Microbiology Laboratory in Winnipeg.

The Canadians were part of a team of international experts who began battling Marburg, a close cousin to Ebola, soon after the world's worst outbreak was detected in March.

Toting the specially designed lab - a collection of equipment worth a modest $\$ 100000$, packed into 8-10 suitcases the Feldmann and Grolla created a field facility that saved physicians and families days, if not weeks, of uncertainty.

Normally, samples are sent to labs elsewhere in Africa or to the US. Instead, Feldmann and Grolla processed between 2 and 30 blood samples daily, providing results within 4 hours.

Testing is essential to the outbreak control efforts of the World Health Organization and Médecins Sans Frontières, since the isolation of confirmed cases is the only defence against the spread of the disease.

Feldmann has studied the Marburg virus for 20 years. The disease first came to the attention of the scientific community in 1967, after monkeys infected lab workers in Marburg, Germany. The virus is spread by close contact with bodily fluids.

They confirmed about onethird of the 266 people diagnosed as of Apr. 20; 244 of those patients have died. "We could have done more, but we didn't get the samples," says Feldmann.

Fearful that the outsiders had brought the virus, many Angolans resisted their approach - there were even reports of some vehicles being stoned. Families often hid sick members and avoided the hospital because with no cure or treatment for the virus, it "had the reputation for being a death trap," Feldmann said.

Some people turned to witch doctors and traditional healers. Often, they received injections of what Feldmann believes were vitamins or herbs in a vain attempt to ward off the virus. Instead, they risked contamination by sharing needles.

By the time patients did ar- rive at the hospital, most were already in the end stages of the disease. All physicians could do was isolate them.

If the blood samples came from a corpse, family members either conducted their traditional burial rites or faced the distressing prospect of seeing the body removed to be burned. Then they had to face the reality that they, too, might be infected and needed to be tested.

To stay focused on their work, Feldmann says they tried not to ask existential questions. "You start thinking, why is this always happening to the poor people of the world - why are they being affected much more by these diseases?"

"Sorry is not enough to say for these people. It's a terrible situation. But that doesn't help you very much in the field."

Still, the helplessness marked them.

"The feeling of not knowing what to do - I could see it in the faces of the people," Feldmann said. "Hoping to the very end that if someone comes down with the fever, that it might be malaria or something else."

One family lost 12 of its 16 members.

As they pulled dead bodies from the makeshift morgue for testing, it was hard not to identify with the families left behind. "Particularly if it's kids. You never forget these faces," Feldmann said.

Colleagues Dr. Jim Strong and biologist Lisa Fernando from Winnipeg took over from Feldmann and Grolla in Uige, and were expected back in May.

Feldmann hopes the worst is over, as more test results werecoming back negative before he left. But uncertainty persisted about the situation in the outlying villages, where $\mathrm{WHO}$ officials were trying to gain a better picture of how many are affected. - Laura Eggertson, CMAJ 